\title{
The Viscosity of R32 and R125 at Saturation
}

\author{
C. M. B. P. Oliveira ${ }^{1}$ and W. A. Wakeham ${ }^{1}$
}

Received May 3, 1993

\begin{abstract}
This paper reports new measurements of the viscosity of R32 and R125, in both the liquid and the vapor phase, over the temperature range 220 to $343 \mathrm{~K}$ near the saturation line. The measurements in both liquid and vapor phases have been carried out with a vibrating-wire viscometer calibrated with respect to standard reference values of viscosity. It is estimated that the uncertainty of the present viscosity data is one of $0.5-1 \%$, being limited partly by the accuracy of the available density data. The experimental data have been represented by polynomial functions of temperature for the purposes of interpolation.
\end{abstract}

KEY WORDS: refrigerants; R32; R125; viscosity.

\section{INTRODUCTION}

Among the fluids considered as substitutes for environmentally harmful refrigerants, R134a has been considered the most suitable for domestic refrigeration applications. However, for other applications, several other fluids or their mixtures are considered more suitable, and among them, R32 and R125 have been identified as potentially useful. In this paper we report upon measurements of the viscosity of these two fluids in both the liquid and the vapor phases along the saturation line.

There have been very few measurements of any of the thermophysical properties of these two fluids so that the present results are the first viscosity measurements for the vapor phase near saturation of either material.

\footnotetext{
${ }^{1}$ Department of Chemical Engineering and Chemical Technology, Imperial College, Prince Consort Road, London SW7 2BY, United Kingdom.
} 


\section{EXPERIMENTS}

The viscosity measurements of the liquid and vapor phases of R32 and R125 have been performed with two different vibrating-wire viscometers. The results obtained with both viscometers have an uncertainty of $\pm 0.5-1 \%$. Since the theory of the instrument has been given in detail elsewhere [1] and a review of the application of the method can be found in Ref. 2, only a brief summary is presented here.

\subsection{Working Equations}

The principle of the vibrating-wire viscometer is that a long thin wire, fixed at both ends, undergoes oscillations normal to its length in the fluid of interest. The decay of free, simple harmonic oscillations of the wire is determined by the viscosity and density of the fluid through the working equation [1]

$$
\Delta=\frac{\left(\rho / \rho_{\mathrm{s}}\right) k^{\prime}+2 A_{0}}{2\left[1+\left(\rho / \rho_{\mathrm{s}}\right) k\right]}
$$

Here $\Delta$ is the logarithmic decrement of the oscillation in the fluid, $\Delta_{0}$ the logarithmic decrement in vacuo, $\rho$ the fluid density, and $\rho_{\mathrm{s}}$ the density of the wire material. In addition, $k$ and $k^{\prime}$ are quantities that depend upon the viscosity of the fluid through the equations [3]

$$
\begin{aligned}
k & =-1+2 \operatorname{Im}(A) \\
k^{\prime} & =2 \operatorname{Re}(A)+2 A \operatorname{Im}(A)
\end{aligned}
$$

where

$$
A=\left(i-\Delta_{0}\right)\left\{1+\frac{2 K_{1}(\mathrm{~s})}{s K_{0}(\mathrm{~s})}\right\}
$$

and

$$
\begin{aligned}
s & =[(i-\Delta) \Omega]^{1 / 2} \\
\Omega & =\frac{\rho \omega R^{2}}{\eta}
\end{aligned}
$$

in which $R$ is the radius of the vibrating wire and $\omega$ the frequency of oscillation. The quantities $K_{0,1}$ are modified Bessel functions.

Evidently, measurement of the decrement and frequency of oscillation of the wire in vacuo and in the fluid, combined with a knowledge of the 
fluid density and the characteristics of the wire itself are sufficient to determine the viscosity of the fluid from Eqs. (1) to (6).

In order to perform absolute viscosity measurements, both the radius $R$ and the density $\rho_{\mathrm{s}}$ of the wire have to be known. Since neither can be measured directly with sufficient accuracy for the sample of material available, it is preferable to perform relative measurements. A calibration of each instrument must therefore be carried out with respect to standard reference viscosities [4].

\subsection{The Liquid Phase Measurements}

The vibrating-wire viscometer employed for the liquid-phase studies has been designed for measurements on liquid hydrocarbons at high pressures [3] and is used here without change. The calibration of the liquid phase viscometer performed earlier [4] is employed in this work.

The liquid phase viscosity of both R32 and R125 has been measured in the temperature range $220-343 \mathrm{k}$ at, or near, saturation. Any departures from the saturation vapor pressure were always small and the effect upon the measured property insignificant. The samples were supplied by ICI Chemicals and Polymers Ltd. with a purity of better than $99.9 \%$, which was confirmed by chromatographic analysis before and after the measurements by techniques identifying both organic and inorganic impurities. The density of the sample liquids has been taken from the representations proposed by McLinden [5].

\subsection{Vapor Phase Measurements}

For the vapor phase viscosity an instrument of the same type was used, but because the kinematic viscosity of the vapor phase differs greatly from that of the liquid phase, quite different characteristics are required of the instrument. A new instrument has therefore been constructed.

Figure 1 shows a schematic diagram of the vapor phase viscometer. It differs in some respects from the liquid phase instrument $[3,4]$, although the essential features remain the same. A brief description is therefore all that is necessary. The vibrating wire (1) consists of a tungsten wire with a nominal diameter of $7.5 \mu \mathrm{m}$ and length $140 \mathrm{~mm}$ suspended from an upper plate by means of a chuck. At its lower end the wire carries a weight of $500 \mathrm{mg}$ (3) which is such that the fundamental frequency of transverse oscillations is $330 \mathrm{~Hz}$. The entire assembly is supported from the cap of a pressure vessel, and in particular, the two samarium-cobalt magnets (2) are held symmetrically with respect to the wire axis in a cage. The magnets serve the same purpose as before $[3,4]$ : to provide a means of initiating 
the wire motion through the interaction of the field with a pulse of current through the wire and to induce a measurable emf between the ends of the wire during its free motion.

Owing to the fact that the effects of buoyancy in the dilute gas are much smaller than in the liquid phase, no buoyancy compensation mechanism is required. Furthermore, compared with the liquid phase viscometer, the changes to the wire radius and vibration frequency reduce the amplitude of the electrical signal to be observed. For that reason, the length of the samarium-cobalt magnets has been increased to retain a similar signal-to-noise ratio to that obtained in the liquid phase system $[3,4]$.

An essential requirement of any instrument for the measurement of the transport properties of fluids is that it operates in accordance with the

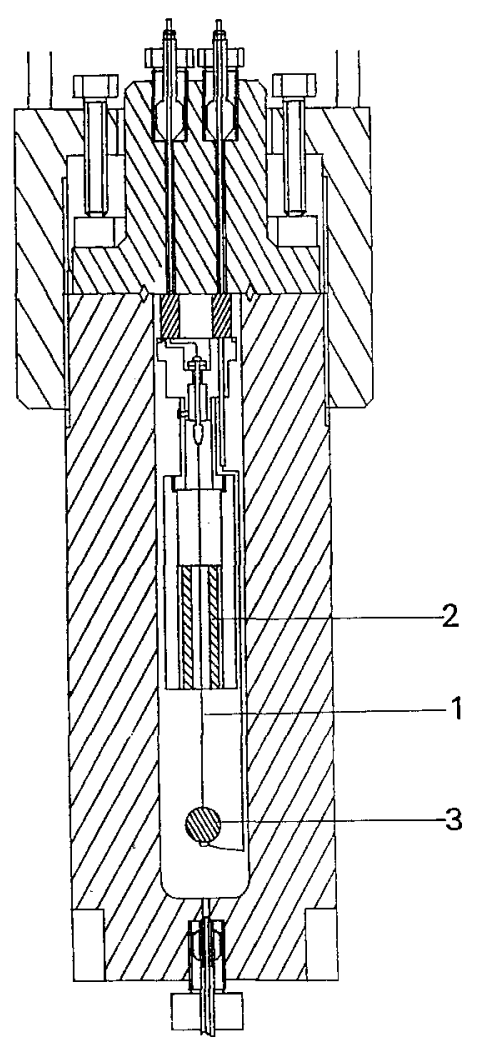

Fig. 1. A schematic diagram of the vapor phase viscometer cell. 
theoretical model of it. To illustrate that the new instrument satisfies this condition, Fig. 2a contains a plot of the transient decay of the wire oscillation when the wire is immersed in nitrogen gas at a temperature of $298 \mathrm{~K}$ and a pressure of $1.5 \mathrm{MPa}$. Figure $2 \mathrm{~b}$ shows the deviations of the recorded data from a representation of them by an equation of the form:

$$
V=A e^{-\Delta \omega t} \sin (\omega t+\varphi)
$$

to which the wire motion should conform [1]. It can be seen that the deviations are small and random so that the wire does indeed move in the manner predicted.
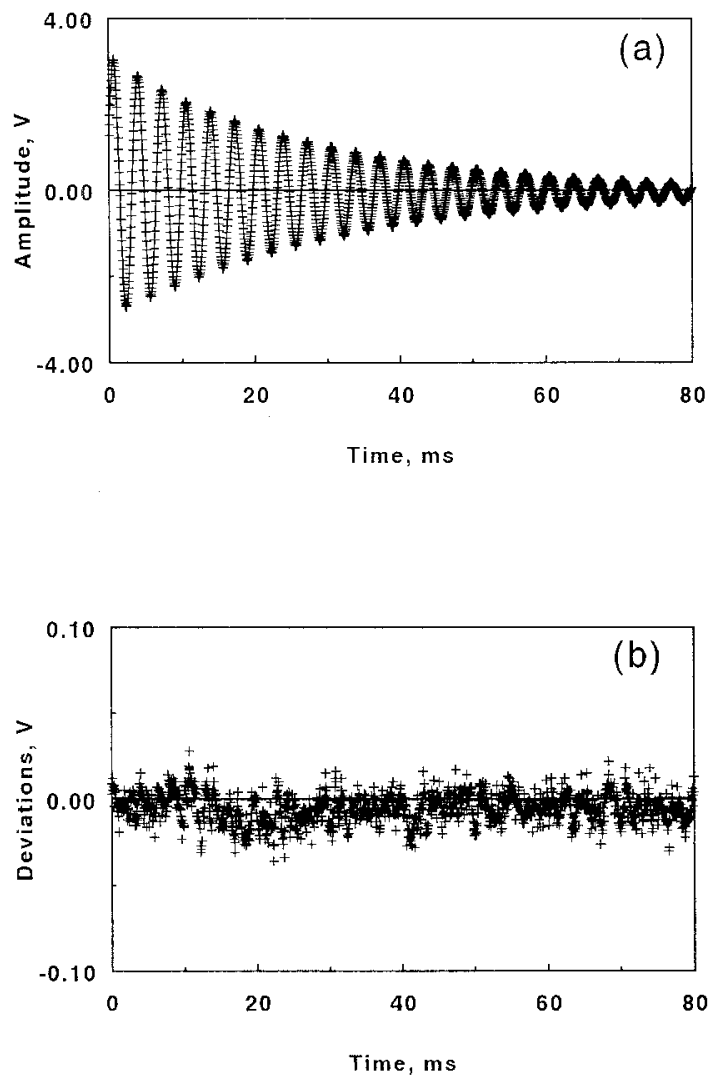

Fig. 2. (a) A typical signal recorded during the transient decay of the wire oscillation in nitrogen gas at a temperature of $298 \mathrm{~K}$ and a pressure of $1.5 \mathrm{MPa}$. (b) The deviation of the data from their optimum representation by Eq. (7). 
It was previously mentioned that in order to perform relative measurements, the vibrating-wire viscometer has to be calibrated. For the vapor phase instrument, this calibration has been carried out with two different gases, nitrogen and helium, over a range of pressures. The calibration has been performed to determine the wire radius, $R$, while the wire density, $\rho_{5}$, has been taken from the liquid phase calibration [4]. The calibration has been performed at a temperature of $298 \mathrm{~K}$ and the results of Kestin et al. [6,7] have been employed as viscosity reference data, whereas the density for the gases has been taken from the equations of state recommended by IUPAC $[8,9]$. The standard reference viscosity data have an uncertainty of no more than $\pm 0.2 \%$ and the uncertainty in the gas density is less than $\pm 0.1 \%$.

Figure 3 shows plots of the wire radius, $R$, for the two gases determined in the fashion as a function of the Reynolds number, $\Omega$. It is evident that the results for the two gases in the region of overlap are entirely consistent and that the radius is independent of $\Omega$. Furthermore, a small number of calibration measurements performed at an elevated temperature for nitrogen, which are included in the figure, are equally consistent. These

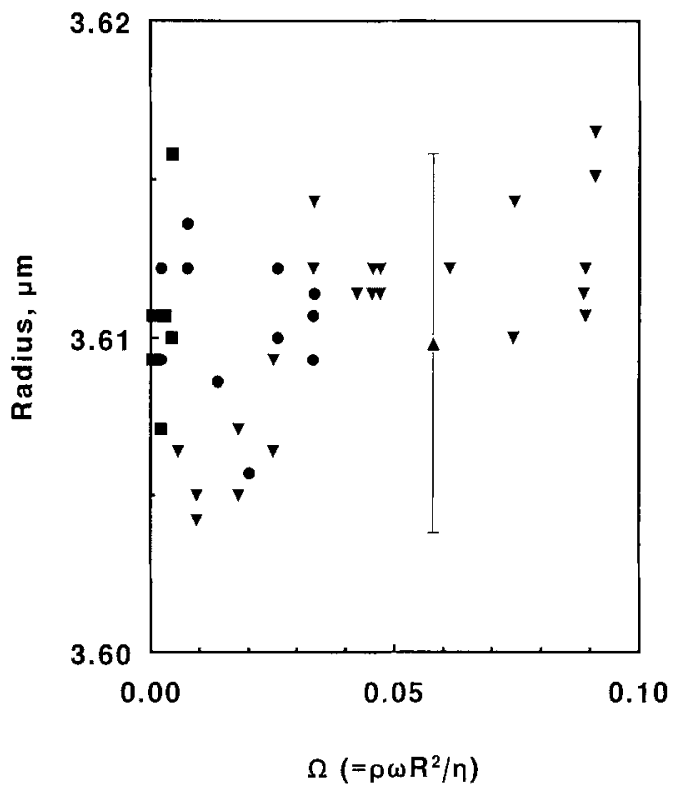

Fig. 3. The calibration of the vapor phase viscometer to determine the wire radius, $R$. ( $\nabla)$ Nitrogen at $25^{\circ} \mathrm{C}$; (๑) nitrogen at $50^{\circ} \mathrm{C} ;(\mathbf{\square})$ helium at $25^{\circ} \mathrm{C}$. 
results provide further evidence of the validity of the experimental technique while leading to an average value for the wire radius $R=3.61 \mu \mathrm{m}$.

The precision and reproducibility of the gas phase viscosity measurements are $\pm 0.5 \%$, whereas, as a result of the calibration process, the accuracy is estimated to be one of $\pm 0.7 \%$, for an error of $\pm 0.1 \%$ in the vapor phase density.

The vapor phase viscosity of both R 32 and R125 was measured in the temperature range $220-335 \mathrm{~K}$ at saturation conditions. Saturation conditions were achieved by maintaining a pool of liquid at the bottom of the pressure vessel containing the viscometer cell at all temperatures. The samples employed for the vapor phase measurements were the same as used in the liquid phase studies and their purity was again confirmed before and after measurement.

The density data for R32 in the vapor phase have been taken from the work of Malbrunot et al. [10], whereas those for R125 have been obtained from Wheelhouse [11]. The latter density data are not as reliable as those for the liquid phase. For this reason, the uncertainty in the viscosity data reported for the vapor phase of R125 may be worse than that for R32 and may be as much as $\pm 1 \%$.

\section{RESULTS}

The results of the viscosity measurements for R 32 and R 125 , in the liquid and vapor phases, are presented in this section, following the same order set our above.

\subsection{Liquid Phase}

Tables I and II list, respectively, the viscosity data for the liquid phase of R32 and R125 at saturation. The viscosity data have an estimated uncertainty of $\pm 0.6 \%$, after account is taken of the uncertainty in the viscosity data employed for calibration, the fluid density, and the precision of the measurements.

For the purposes of comparison the data have been represented by an equation of the form

$$
\eta_{\mathrm{L}} / \eta_{\mathrm{L}}(T=300 \mathrm{~K})=\exp \left\{\sum_{i=0}^{3} a_{i}(300 / T)^{i}\right\}
$$

where $T$ is measured in $\mathrm{K}$, and the coefficients are included in Table III.

A plot of the deviations of the present viscosity data for liquid R32 from the optimum representation is shown in Fig. 4. It can be seen that the maximum deviation of the experimental results amounts to $\pm 0.8 \%$, 
Table I. Viscosity of Liquid R32 at Saturation

\begin{tabular}{cccc}
\hline $\begin{array}{c}\text { Temperature } \\
T(\mathrm{~K})\end{array}$ & $\begin{array}{c}\text { Pressure } \\
P(\mathrm{MPa})\end{array}$ & $\begin{array}{c}\text { Density } \\
\rho\left(\mathrm{kg} \cdot \mathrm{m}^{-3}\right)\end{array}$ & $\begin{array}{c}\text { Viscosity } \\
\eta(\mathrm{mPa} \cdot \mathrm{s})\end{array}$ \\
\hline 231.80 & 0.210 & 1180.8 & 0.2434 \\
237.13 & 0.310 & 1165.9 & 0.2274 \\
244.00 & 0.408 & 1146.2 & 0.2112 \\
245.22 & 0.555 & 1142.7 & 0.2094 \\
253.25 & 0.520 & 1118.6 & 0.1908 \\
257.00 & 0.852 & 1107.1 & 0.1848 \\
262.56 & 0.897 & 1089.5 & 0.1734 \\
269.15 & 0.980 & 1067.9 & 0.1610 \\
272.44 & 0.943 & 1056.8 & 0.1545 \\
272.79 & 0.999 & 1055.6 & 0.1541 \\
280.51 & 1.154 & 1028.6 & 0.1418 \\
285.09 & 1.367 & 1011.7 & 0.1342 \\
287.46 & 1.455 & 1002.8 & 0.1300 \\
294.79 & 1.803 & 974.0 & 0.1194 \\
304.73 & 2.225 & 931.7 & 0.1055 \\
313.11 & 2.464 & 892.1 & 0.0944 \\
323.13 & 3.267 & 838.0 & 0.0836 \\
333.60 & 4.069 & 768.5 & 0.0712 \\
343.14 & 5.107 & 680.1 & 0.0624 \\
\hline
\end{tabular}

Table II. Viscosity of Liquid R125 at Saturation

\begin{tabular}{cccc}
\hline $\begin{array}{c}\text { Temperature } \\
T(\mathrm{~K})\end{array}$ & $\begin{array}{c}\text { Pressure } \\
P(\mathrm{MPa})\end{array}$ & $\begin{array}{c}\text { Density } \\
\rho\left(\mathrm{kg} \cdot \mathrm{m}^{-3}\right)\end{array}$ & $\begin{array}{c}\text { Viscosity } \\
\eta(\mathrm{mPa} \cdot \mathrm{s})\end{array}$ \\
\hline 251.95 & 0.366 & 1470.8 & 0.2523 \\
255.22 & 0.531 & 1394.9 & 0.2418 \\
259.51 & 0.468 & 1377.7 & 0.2302 \\
264.70 & 0.809 & 1356.0 & 0.2156 \\
270.63 & 0.661 & 1330.3 & 0.2000 \\
275.41 & 0.759 & 1308.5 & 0.1884 \\
286.62 & 1.043 & 1253.8 & 0.1649 \\
296.84 & 1.343 & 1197.8 & 0.1461 \\
304.49 & 1.668 & 1150.3 & 0.1335 \\
306.98 & 1.699 & 1133.6 & 0.1299 \\
314.58 & 2.148 & 1077.5 & 0.1192 \\
323.09 & 2.608 & 1001.0 & 0.1075 \\
333.19 & 3.960 & 867.7 & 0.0965 \\
\hline
\end{tabular}


Table III. Coefficients in the Representation of the Liquid Phase Viscosity of R32 and R125

\begin{tabular}{lcrccc}
\hline Fluid & $\begin{array}{c}\eta(T=300 \mathrm{~K}) \\
(\mathrm{mPa} \cdot \mathrm{s})\end{array}$ & \multicolumn{1}{c}{$a_{0}$} & $a_{1}$ & \multicolumn{1}{c}{$a_{2}$} & \multicolumn{1}{c}{$a_{3}$} \\
\hline $\mathrm{R} 32$ & 0.1128 & -17.16591 & 37.9006 & -28.10334 & 7.359732 \\
$\mathrm{R} 125$ & 0.1407 & -7.32664 & 12.3198 & -6.17818 & 1.18514 \\
\hline
\end{tabular}

whereas the standard deviation is one of $\pm 0.4 \%$, which is consistent with the estimated precision. The same figure contains a comparison with the results of Matar and Ripple [12], performed in a suspended-level, coiledcapillary viscometer; the deviations between the two sets of measurements are as large as $12 \%$, which greatly exceeds the combined, estimated uncertainty. The deviations also have a substantial temperature dependence.

Figure 5 shows the deviations of the present experimental viscosity data for R125 from their optimum representation; it can be seen that the maximum deviation amounts to $\pm 0.4 \%$, with a standard deviation of $\pm 0.2 \%$. The same figure contains a comparison with earlier work. The

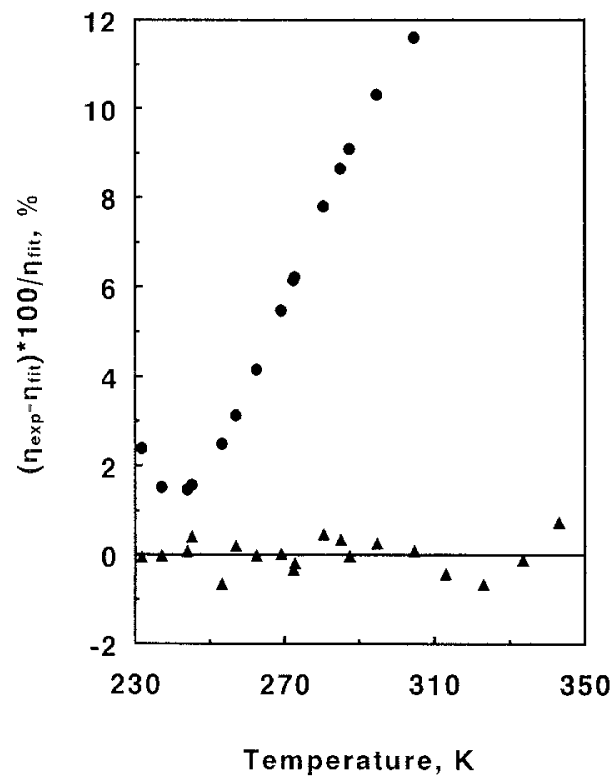

Fig. 4. Deviations of the experimental viscosity data for R32 along the saturation line in the liquid phase from the representation of them by Eq. (10).

(A) Present work; (๑) Matar and Ripple [12]. 


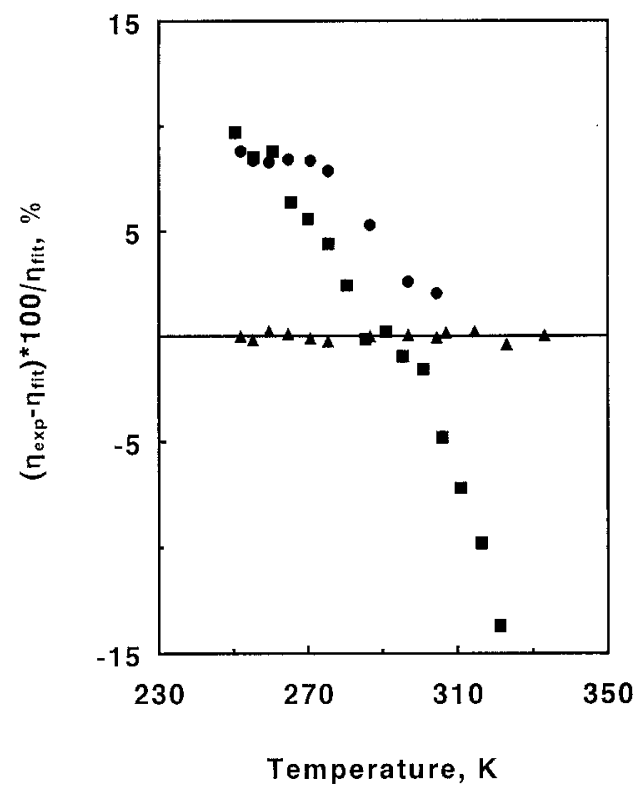

Fig. 5. Deviations of the experimental viscosity data for R125 along the saturation line in the liquid phase from the representation of them by Eq. (10). (ム) Present work; (@) Ripple [13]; (ロ) Diller [14].

data of Ripple [13] depart from the present representation by as much as $8 \%$, while the data of Diller et al. [14], obtained with an oscillating quartz-crystal viscometer, deviate from the present representation by as much as $-20 \%$. It is noticeable that all three sets of results are almost entirely consistent, close to ambient temperature.

\subsection{Vapor Phase}

Tables IV and V list, respectively, the viscosity data for the vapor phase of R32 and R125 near saturation. As noted earlier, the accuracy of the data is limited by the uncertainty in the vapor phase density, since these errors propagate directly. Therefore, after account is taken of the uncertainty in the viscosity data employed for calibration, the fluid density, and the precision of the measurements, the viscosity data of R32 have an estimated uncertainty of $\pm 0.7 \%$. For R 125 , owing to the lack of reliable equation of state, the density data used have a larger uncertainty. As a consequence, the viscosity data reported for R125 are burdened with a substantially greater error, which is estimated to be one of $\pm 1 \%$. It should 
Table IV. Viscosity of R32 in the Vapor Phase at Saturation

\begin{tabular}{cccc}
\hline $\begin{array}{c}\text { Temperature } \\
T(\mathrm{~K})\end{array}$ & $\begin{array}{c}\text { Pressure } \\
P(\mathrm{MPa})\end{array}$ & $\begin{array}{c}\text { Density } \\
\rho\left(\mathrm{kg} \cdot \mathrm{m}^{-3}\right)\end{array}$ & $\begin{array}{c}\text { Viscosity } \\
\eta(\mu \mathrm{Pa} \cdot \mathrm{s})\end{array}$ \\
\hline 223.17 & 0.136 & 4.047 & 10.320 \\
238.87 & 0.259 & 7.339 & 10.461 \\
251.88 & 0.416 & 11.51 & 10.722 \\
261.31 & 0.440 & 14.63 & 10.990 \\
268.68 & 0.705 & 19.07 & 11.237 \\
273.50 & 0.798 & 21.43 & 11.412 \\
278.81 & 0.899 & 23.91 & 11.679 \\
292.81 & 1.411 & 38.38 & 12.366 \\
297.97 & 1.555 & 41.99 & 12.636 \\
303.11 & 1.914 & 53.90 & 12.998 \\
313.25 & 2.489 & 73.20 & 13.812 \\
323.05 & 3.158 & 99.12 & 14.601 \\
335.13 & 4.047 & 137.87 & 16.186 \\
343.23 & 4.849 & 188.61 & 17.397 \\
\hline
\end{tabular}

be noted that the reevaluation of the vapor phase viscosity is relatively straightforward given improved density data since the original data for the present experiments are held on file.

For the purposes of interpolation the data for the vapor phase viscosity have been represented by an equation of the from

$$
\eta_{\mathrm{V}}=\frac{C(T M / 300)^{1 / 2}}{\sum_{i-0}^{2} b_{i}(T / 300)^{i}}
$$

Table V. Viscosity of R125 in the Vapor Phase at Saturation

\begin{tabular}{cccc}
\hline $\begin{array}{c}\text { Temperature } \\
T(\mathrm{~K})\end{array}$ & $\begin{array}{c}\text { Pressure } \\
P(\mathrm{MPa})\end{array}$ & $\begin{array}{c}\text { Density } \\
\rho\left(\mathrm{kg} \cdot \mathrm{m}^{-3}\right)\end{array}$ & $\begin{array}{c}\text { Viscosity } \\
\eta(\mu \mathrm{Pa} \cdot \mathrm{s})\end{array}$ \\
\hline 223.99 & 0.108 & 6.66 & 10.223 \\
232.44 & 0.143 & 9.75 & 10.469 \\
244.04 & 0.250 & 15.7 & 10.991 \\
253.66 & 0.330 & 22.5 & 11.380 \\
263.23 & 0.473 & 31.3 & 11.848 \\
273.48 & 0.675 & 43.4 & 12.399 \\
284.24 & 0.968 & 59.8 & 13.076 \\
293.61 & 1.208 & 78.3 & 13.720 \\
298.11 & 1.413 & 89.1 & 14.063 \\
303.24 & 1.579 & 103.6 & 14.468 \\
313.45 & 2.026 & 141.6 & 15.399 \\
323.18 & 2.424 & 194.9 & 16.428 \\
331.99 & 2.913 & 250.3 & 19.110 \\
\hline
\end{tabular}


Table VI. Coefficients in the Representation of the Vapor Phase Viscosity of R32 and R125

\begin{tabular}{lccccc}
\hline Fluid & $\begin{array}{c}\text { Relative } \\
\text { molar mass }\end{array}$ & $\begin{array}{c}C \\
(\mu \mathrm{Pa} \cdot \mathrm{s})\end{array}$ & $b_{0}$ & $b_{1}$ & \multicolumn{1}{c}{$b_{2}$} \\
\hline R32 & 52.04 & 1.77125 & -0.9806 & 5.00707 & -3.026868 \\
R125 & 120.02 & 1.93667 & 0.9432 & 2.8895 & -2.33966 \\
\hline
\end{tabular}

in which $T$ is measured in $\mathrm{K}, M$ is the relative molecular mass of the refrigerant, and the remaining coefficients are given in Table VI.

There are, to our knowledge, no other measurements of the viscosity of the vapor phase of either R32 or R125, along the saturation line. Consequently, Fig. 6 contains a comparison only of the present data with the optimum representation. It can be seen that for R32 the maximum deviation amounts to $\pm 0.8 \%$, with a standard deviation of $\pm 0.4 \%$, whereas the maximum deviations for R125 amount to $\pm 0.4 \%$, with a standard deviation of $\pm 0.2 \%$.

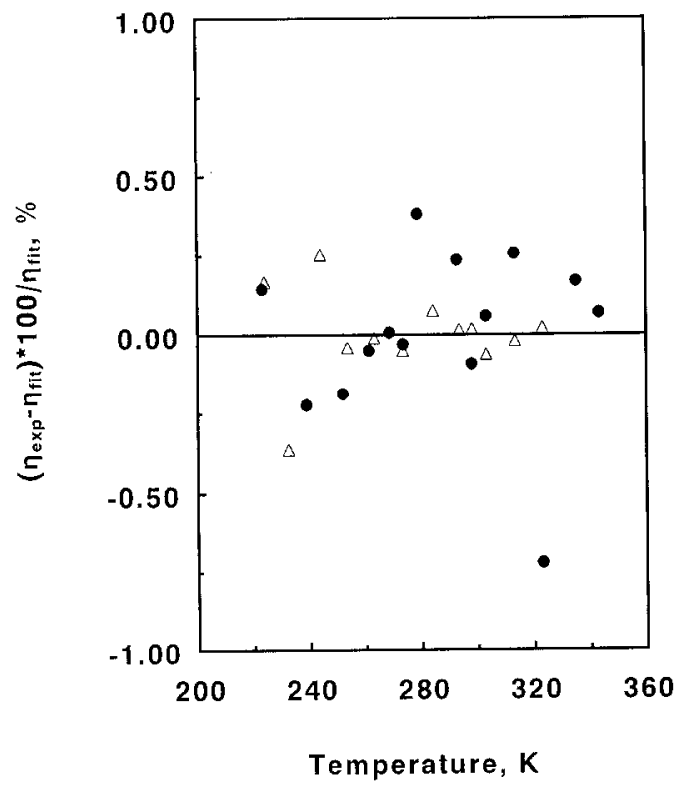

Fig. 6. A comparison between the present measurements of the viscosity of $\mathrm{R} 32$ and $\mathrm{R} 125$ vapor near saturation and the representation of them by means of Eq. (11). (๑) R32; ( $\triangle$ ) R125. 


\section{CONCLUSION}

The viscosity data reported for R32 and R125 in the liquid phase depart from those reported by the other authors using different instruments under comparable conditions. The situation is therefore similar to that encountered for R134a in the early stages of the study of that fluid and reviewed elsewhere [15]. The reasons for those early discrepancies and those revealed here remain obscure and further systematic studies are obviously required. In the vapor phase, the present results represent the first obtained near the saturation line so that further, independent measurements over a range of pressures will now be required to determine the viscosity below the saturation vapor pressure.

\section{ACKNOWLEDGMENTS}

The authors are grateful to ICI Chemicals and Polymers Ltd. for the supply of the fluid samples and the chemical analyses of purity. The authors particularly wish to thank Dean Ripple, Omar Matar, and Dwain Diller for allowing them access to their experimental results prior to publication. Mr. M. Dix continued to make invaluable contributions to the maintenance of the viscometers in good working order.

\section{REFERENCES}

1. T. Retsina, S. M. Richardson, and W. A. Wakeham, Appl. Sci. Res. 43:325 (1987).

2. P. S. van der Gulik, in Experimental Thermodynamics III, Measurement of the Transport Properties of Fluids, W. A. Wakeham, A. Nagashima, and J. V. Sengers, eds. (Blackwell Scientific, Oxford, 1991), Chap. 4.

3. C. M. B. P. Oliveira and W. A. Wakeham, Int. J. Thermophys. 13:5 (1992).

4. M. J. Assael, C. P. Oliveira, M. Papadaki, and W. A. Wakeham, Int. J. Thermophys. 13:4 (1992).

5. M. O. McLinden, Rev. Int. Froid 13:149 (1990).

6. J. Kestin and W. Leidenfrost, Physica 25:1033 (1959).

7. J. Kestin, E. Paykoc, and J. V. Sengers, Physica 54:1 (1971).

8. S. Angus, K. M. de Reuck, and B. Armstrong, International Thermodynamic Tables of the Fluid State, Nitrogen, Vol. 6 (Pergamon Press, 1979).

9. S. Angus, K. M. de Reuck, and R. D. McCarthy, International Thermodynamic Tables of the Fluid State, Helium, Vol. 4 (Pergamon Press, 1979).

10. P. F. Malbrunot, P. A. Meuniere, G. M. Scotana, W. H. Mears, K. P. Murphy, and J. V. Sinka, J. Chem. Eng. Data 13:16 (1968).

11. R. Wheelhouse, private communication (1992).

12. O. Matar and D. Ripple, in press (1992).

13. D. Ripple, 1992, private communication.

14. D. E. Diller, in press (1992).

15. C. M. B. P. Oliveira and W. A. Wakeham, Proceedings of the PROTECT Workshop on Thermophysical Properties of Refrigerants, Ericeira, Portugal, Nov. (1992). 